\title{
A viscosity iterative algorithm for split common fixed-point problems of demicontractive mappings
}

Di Gao ${ }^{a}$, Tae Hwa Kima,*, Yaqin Wang ${ }^{\mathrm{b}}$

${ }^{a}$ Department of Applied Mathematics, College of Natural Sciences, Pukyong National University, Busan 48513, Republic of Korea.

${ }^{b}$ Department of Mathematics, Shaoxing University, Shaoxing 312000, China.

Communicated by R. Saadati

\begin{abstract}
In this paper, we firstly introduce a new viscosity cyclic iterative algorithm for the split common fixed-point problem (SCFP) of demicontractive mappings. Next we prove the strong convergence of the sequence generated recursively by such a viscosity cyclic algorithm to a solution of the SCFP, which improves and extends some recent corresponding results.
\end{abstract}

Keywords: Multiple-set split equality common fixed-point problem, demicontractive mapping, viscosity cyclic iterative algorithm, strong convergence.

2010 MSC: 47H05, 47H09, 47J10, 47H20.

(C) 2018 All rights reserved.

\section{Introduction}

Let $\mathrm{C}$ and $\mathrm{Q}$ be nonempty closed convex subsets of real Hilbert spaces $\mathrm{H}_{1}$ and $\mathrm{H}_{2}$, respectively, and let A : $\mathrm{H}_{1} \rightarrow \mathrm{H}_{2}$ be a bounded linear operator. The split feasibility problem (SFP) which originally introduced in Censor and Elfving [1] is to find a point $x^{*} \in \mathrm{C}$ with the property:

$$
x^{*} \in C \text { and } A x^{*} \in Q \text {. }
$$

It serves as a model for many inverse problems where constraints are imposed on the solutions in the domain of a linear operator as well as in this operator's ranges. There are a number of significant applications of the SFP in intensity-modulated radiation therapy, signal processing, image reconstruction and so on.

In the case where C and Q in the SFP (1.1) are the intersections of finitely many fixed-point sets of nonlinear operators, the problem (1.1) is called by Censor and Segal [2] the split common fixed-point problem (SCFP). More precisely, the SCFP requires to seek an element $x^{*} \in \mathrm{H}_{1}$ satisfying

$$
x^{*} \in \cap_{i=1}^{p} \operatorname{Fix}\left(U_{i}\right) \text { and } A x^{*} \in \cap_{j=1}^{q} \operatorname{Fix}\left(T_{j}\right),
$$

\footnotetext{
*Corresponding author

Email addresses: kekeke.444@163.com (Di Gao), taehwa@pknu.ac.kr (Tae Hwa Kim), wangyaqin0579@126.com (Yaqin Wang)

doi: $10.22436 /$ jnsa.011.11.02
}

Received: 2017-05-30 Revised: 2018-07-17 Accepted: 2018-07-24 
where $p, q \geqslant 1$ are integers, and $\operatorname{Fix}\left(U_{i}\right)$ and $\operatorname{Fix}\left(T_{j}\right)$ denote the fixed point sets of two classes of nonlinear operators $U_{i}: H_{1} \rightarrow H_{1}(i=1,2, \cdots, p), T_{j}: H_{2} \rightarrow H_{2}(j=1,2, \cdots, q)$. In particular, if $p=q=1$, the problem (1.2) is reduced to find a point $x^{*}$ with the property:

$$
x^{*} \in \operatorname{Fix}(\mathrm{U}) \text { and } A x^{*} \in \operatorname{Fix}(T),
$$

which is usually called the two-set SCFP. To solve the two-set SCFP (1.3), Censor and Segal [2] proposed the following iterative method: for any initial guess $x_{1} \in \mathrm{H}_{1}$, define $\left\{x_{n}\right\}$ recursively by

$$
x_{n+1}=U\left(x_{n}-\lambda A^{*}(I-T) A x_{n}\right),
$$

where $\mathrm{U}$ and $\mathrm{T}$ are directed operators. The further generalization of this algorithm has been studied by Moudafi [10] for demicontractive operators. Under suitable conditions he proved that the sequence $\left\{x_{n}\right\}$ converges weakly to a point of the two-set SCFP (1.3).

Recall that, for a fixed positive integer $p$ and each $n \geqslant 0$, the $p$-mod function $[n]$ is defined by

$$
[n]= \begin{cases}p, & \text { if } r=0, \\ r, & \text { if } 0<r<p,\end{cases}
$$

whenever $n=k p+r$ for some $k \geqslant 0$. Afterwards, the $p$-mod function will be sometimes written as $[n]=n(\bmod p)$ in case distinction of $p$ is needed. Recently, Wang and $\mathrm{Xu}$ [14] proposed the following cyclic algorithm:

$$
x_{n+1}=U_{[n]}\left(x_{n}-\lambda A^{*}\left(I-T_{[n]}\right) A x_{n}\right),
$$

where $U_{i}$ and $T_{i}$ are directed operators for $i=1,2, \ldots, p$. They proved that the sequence $\left\{x_{n}\right\}$ generated by the algorithm (1.4) converges weakly to a solution of the problem (1.2) in a case when $p=q$.

Noticing that the existing algorithm for the SCFP (1.2) have only weak convergence in infinite dimensional spaces (see [10, 14]), in 2013, Cui et al. [3] constricted the following cyclic iterative procedure, motivated by Eicke's damped projection algorithm [5], so that strong convergence is guaranteed: given $x_{1} \in H_{1}$ and a positive integer $p$, define a sequence $\left\{x_{n}\right\}$ by the iterative procedure

$$
x_{n+1}=\left(1-\alpha_{n}\right) x_{n}+\alpha_{n} U_{[n]}\left[\left(1-\alpha_{n}\right)\left(x_{n}-\lambda_{n} A^{*}\left(I-T_{[n]}\right) A x_{n}\right)\right], \quad n \geqslant 1,
$$

where $U_{i}$ and $T_{i}$ are directed operators for $i=1,2, \ldots, p,\left\{\alpha_{n}\right\} \subset(0,1)$ and $\left\{\lambda_{n}\right\} \subset \mathbb{R}^{+}$are properly chosen real sequences. Under some suitable conditions of parameters, they proved that the sequence $\left\{x_{n}\right\}$ generated recursively by (1.5) converges strongly to a solution of the problem (1.2) provided $p=q$.

Very recently, He et al. [6] developed the following viscosity algorithm to approximate the solution of the two-set SCFP (1.3) for demicontractive mappings

$$
x_{n+1}=\alpha_{n} f\left(x_{n}\right)+\left(1-\alpha_{n}\right) U_{\lambda}\left(x_{n}-\rho_{n} A^{*}(I-T) A x_{n}\right), \quad n \geqslant 0
$$

equipped with the step size

$$
\rho_{n}= \begin{cases}\frac{(1-\eta)\left\|(I-T) A x_{n}\right\|^{2}}{2\left\|A^{*}(I-T) A x_{n}\right\|^{2}}, & A x_{n} \neq T\left(A x_{n}\right), \\ 0, & \text { otherwise }\end{cases}
$$

where $\mathrm{U}: \mathrm{H}_{1} \rightarrow \mathrm{H}_{1}$ and $\mathrm{T}: \mathrm{H}_{2} \rightarrow \mathrm{H}_{2}$ are $\mu$ and $\eta$-demicontractive mappings, respectively, $\mathrm{U}_{\lambda}=(1-$ $\lambda) I+\lambda U$ for $\lambda \in(0,1-\mu)$, f denotes a fixed contraction in $\operatorname{Fix}(U)$ and $\left\{\alpha_{n}\right\} \subset(0,1)$ is a real sequence satisfying $\lim _{n \rightarrow \infty} \alpha_{n}=0$ and $\sum_{n=0}^{\infty} \alpha_{n}=\infty$. Then they established that the sequence $\left\{x_{n}\right\}$ generated recursively by (1.6) converges strongly to a solution $\hat{x}$ of the two-set SCFP (1.3), and the $\hat{x}$ solves the following variational inequality:

$$
\langle\hat{x}-f(\hat{x}), \hat{x}-z\rangle \leqslant 0, \quad \forall z \in \Lambda,
$$

where $\wedge$ denotes the set of all solutions of the two-set SCFP (1.3). 
In this paper, inspired and motivated by $[6,14]$, we first consider the following cyclic algorithm of the SCFP (1.2) for demicontractive mappings: given an initial guess $x_{0} \in \mathrm{H}_{1}$ and two positive integers $p$ and $q$, let a sequence $\left\{x_{n}\right\}$ generated recursively by

$$
x_{n+1}=\alpha_{n} f\left(x_{n}\right)+\left(1-\alpha_{n}\right) U_{\lambda_{n}}\left(x_{n}-\rho_{n} A^{*}\left(I-T_{[n]}\right) A x_{n}\right), \quad \forall n \geqslant 0,
$$

where $U_{i}$ is $\mu_{i}$-demicontractive, $T_{j}$ is $\eta_{j}$-demicontractive for $i \leqslant i \leqslant p, 1 \leqslant j \leqslant q, \mu=\max _{1 \leqslant i \leqslant p} \mu_{i}$,

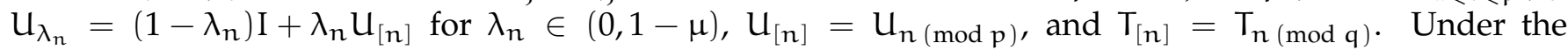
conditions of $\left\{\alpha_{n}\right\}$ in (1.6), we next prove that the sequence $\left\{x_{n}\right\}$ defined recursively by (1.7) converges strongly to a solution $\hat{x}$ of the SCFP (1.2), and the $\hat{x}$ solves the following variational inequality:

$$
\langle\hat{x}-\mathrm{f}(\hat{x}), \hat{x}-z\rangle \leqslant 0, \quad \forall z \in \Omega,
$$

where

$$
\Omega:=\left(\cap_{i=1}^{p} \operatorname{Fix}\left(U_{i}\right)\right) \cap A^{-1}\left(\cap_{j=1}^{q} \operatorname{Fix}\left(T_{j}\right)\right)
$$

denotes the solution set of the SCFP (1.2).

\section{Preliminaries}

Let $\mathrm{H}$ be a real Hilbert space with the norm $\|\cdot\|$ induced by the inner product $\langle\cdot, \cdot\rangle$. When $\left\{x_{n}\right\}$ is a sequence in $H$, we denote the strong convergence and the weak convergence of $\left\{x_{n}\right\}$ to $x \in H$ by $x_{n} \rightarrow x$ and $x_{n} \rightarrow x$, respectively. We also denote by $\operatorname{Fix}(T)$ the set of fixed points of $T$. We use $\omega_{w}\left(x_{n}\right)=\left\{x: \exists x_{n_{k}} \rightarrow x\right\}$ to stand for weak $\omega$-limit set of $\left\{x_{n}\right\}$. Also we need the following inequality which is very crucial for our argument:

$$
\|x+y\|^{2} \leqslant\|x\|^{2}+2\langle y, x+y\rangle, \quad \forall x, y \in H .
$$

Definition 2.1. An operator $\mathrm{T}: \mathrm{H} \rightarrow \mathrm{H}$ is said to be:

(i) nonexpansive if

(ii) quasi-nonexpansive if

$$
\|T x-T y\| \leqslant\|x-y\|, \quad \forall x, y \in H
$$

$$
\|\mathrm{T} x-z\| \leqslant\|x-z\|, \quad \forall(x, z) \in \mathrm{H} \times \operatorname{Fix}(\mathrm{T})
$$

(iii) directed if

$$
\langle z-T x, x-T x\rangle \leqslant 0, \quad \forall(x, z) \in H \times \operatorname{Fix}(T),
$$

equivalently,

$$
\|\mathrm{T} x-z\|^{2} \leqslant\|x-z\|^{2}-\|x-\mathrm{T} x\|^{2}, \quad \forall(x, z) \in \mathrm{H} \times \operatorname{Fix}(\mathrm{T}) ;
$$

(iv) $\mu$-demicontractive if $\operatorname{Fix}(T) \neq \emptyset$ and there exists a constant $\mu \in(-\infty, 1)$ such that

$$
\|\mathrm{T} x-z\|^{2} \leqslant\|x-z\|^{2}+\mu\|x-\mathrm{T} x\|^{2}, \quad \forall(x, z) \in \mathrm{H} \times \operatorname{Fix}(\mathrm{T}),
$$

which is equivalent to

$$
\langle z-T x, x-T x\rangle \leqslant \frac{1+\mu}{2}\|x-T x\|^{2}, \quad \forall(x, z) \in H \times \operatorname{Fix}(T) .
$$

It is worth noting that the class of demicontractive mappings contain important operators such as quasi-nonexpansive mappings and directed mappings.

Remark 2.2. Notice that 0 -demicontractive is exactly quasi-nonexpansive. In particular, we say that $\mathrm{T}: \mathrm{H} \rightarrow$ $\mathrm{H}$ is quasi-strictly pseudo-contractive [9] if (iv) in Definition 2.1 is satisfied with $0 \leqslant \mu<1$. Moreover, if $\mu \leqslant 0$, every $\mu$-demicontractive mapping becomes quasi-nonexpansive. So, it seems to be sufficient to only take $\mu \in(0,1)$ in (iv) of Definition 2.1 in Hilbert spaces. However, as seen in (iii) of Definition 2.1, every directed operator is $(-1)$-demicontractive. 
Definition 2.3. Let $\mathrm{T}: \mathrm{H} \rightarrow \mathrm{H}$ be an operator, then $\mathrm{I}-\mathrm{T}$ is said to be demiclosed at zero whenever, for any sequence $\left\{x_{n}\right\} \subset H$ satisfying that $x_{n} \rightarrow x \in H$ and $(I-T) x_{n} \rightarrow 0$, it results $x=T x$.

Lemma 2.4 ([15, Lemma 2.1]). $\left\{\beta_{n}\right\}$ is a sequence of nonnegative real numbers such that

$$
\beta_{n+1} \leqslant\left(1-\gamma_{n}\right) \alpha_{n}+\delta_{n}, \quad n \geqslant 0,
$$

where $\left\{\gamma_{n}\right\}$ is a sequence in $(0,1)$ and $\left\{\delta_{n}\right\}$ is a sequence in $R$ such that

(i) $\sum_{n=1}^{\infty} \gamma_{n}=\infty$;

(ii) $\limsup _{n \rightarrow \infty} \frac{\delta_{n}}{\gamma_{n}} \leqslant 0$ or $\sum_{n=1}^{\infty}\left|\delta_{n}\right| \leqslant \infty$.

Then $\lim _{n \rightarrow \infty} \alpha_{n}=0$.

Lemma 2.5 ([4, Lemmas 2.5 and 2.6]). $\mathrm{A}: \mathrm{H}_{1} \rightarrow \mathrm{H}_{2}$ be a bounded linear operator and $\mathrm{T}: \mathrm{H}_{2} \rightarrow \mathrm{H}_{2}$ be a $\eta$-demicontractive, $\eta<1$, if $A^{-1} \operatorname{Fix}(T) \neq \emptyset$, then,

(a) $(\mathrm{I}-\mathrm{T}) \mathrm{Ax}=0 \Leftrightarrow \mathrm{A}^{*}(\mathrm{I}-\mathrm{T}) \mathrm{Ax}=0, \quad \forall x \in \mathrm{H}_{1}$;

(b) in addition, for $z \in A^{-1} \operatorname{Fix}(T)$,

$$
\left\|x-\rho A^{*}(I-T) A x-z\right\|^{2} \leqslant\|x-z\|^{2}-\frac{(1-\eta)^{2}}{4} \frac{\|(I-T) A x\|^{4}}{\left\|A^{*}(I-T) A x\right\|^{2}}
$$

where $x \in \mathrm{H}_{1}, \mathrm{Ax} \neq \mathrm{T}(\mathrm{Ax})$ and

$$
\rho:=\frac{1-\eta}{2} \frac{\|(\mathrm{I}-\mathrm{T}) A x\|^{2}}{\left\|A^{*}(\mathrm{I}-\mathrm{T}) A x\right\|^{2}}
$$

Lemma 2.6 ([10, (1.7)] or [4, Lemma 2.4]). Let $\mathrm{U}: \mathrm{H}_{1} \rightarrow \mathrm{H}_{1}$ be a $\mu$-demicontractive operator with $\mu<1$. Denote $\mathrm{U}_{\lambda}:=(1-\lambda) \mathrm{I}+\lambda \mathrm{U}$ for $\lambda \in(0,1-\mu)$. Then for any $\mathrm{x} \in \mathrm{H}_{1}$ and $z \in \operatorname{Fix}(\mathrm{U})$,

$$
\left\|\mathrm{U}_{\lambda} x-z\right\|^{2} \leqslant\|x-z\|^{2}-\lambda(1-\mu-\lambda)\|(\mathrm{I}-\mathrm{U}) x\|^{2} .
$$

Lemma 2.7 ([9, Proposition 2.1]). Assume $\mathrm{C}$ is a nonempty closed convex subset of a Hilbert space $\mathrm{H}$. If $\mathrm{T}: \mathrm{C} \rightarrow \mathrm{C}$ is a $\mu$-demicontractive mapping (which is also called $\mu$-quasi-strict pseudo-contraction in [9]), then the fixed point set $\mathrm{F}(\mathrm{T})$ is closed and convex.

Lemma 2.8 ([8, Lemma 3.1]). Let $\left\{\Gamma_{\mathrm{n}}\right\}$ be a sequence of real numbers that does not decrease at infinity in the sense that there exists a subsequence $\left\{\Gamma_{n_{i}}\right\}$ of $\left\{\Gamma_{n}\right\}$ which satisfies $\Gamma_{n_{i}}<\Gamma_{n_{i}+1}$ for all $i \geqslant 0$. Define the sequence $\{\tau(n)\}_{n} \geqslant n_{0}$ of integers as follows:

$$
\tau(n)=\max \left\{k \leqslant n: \Gamma_{k}<\Gamma_{k+1}\right\},
$$

where $\mathrm{n}_{0} \in \mathbb{N}$ such that $\left.\left\{\mathrm{k} \leqslant \mathrm{n}_{0}: \Gamma_{\mathrm{k}}<\Gamma_{\mathrm{k}+1}\right\}\right\} \neq \emptyset$. Then the following properties hold

(i) $\tau\left(n_{0}\right) \leqslant \tau\left(n_{0}+1\right) \leqslant \cdots$ and $\tau(n) \rightarrow \infty$;

(ii) $\Gamma_{\tau(n)} \leqslant \Gamma_{\tau(n)+1}$ and $\Gamma_{n} \leqslant \Gamma_{\tau(n)+1}, \forall n \geqslant n_{0}$.

Recall that if $\mathrm{C}$ is a nonempty closed convex subset of a Hilbert space $\mathrm{H}$, the metric (or nearest point) projection from $\mathrm{H}$ onto $\mathrm{C}$ is the mapping $\mathrm{P}: \mathrm{H} \rightarrow \mathrm{C}$ which assigns to each point $x \in \mathrm{H}$ the unique point $P_{C} x \in C$ satisfying the property

$$
\left\|x-P_{C} x\right\|=\inf _{y \in C}\|x-y\| .
$$

Lemma 2.9 ([11, Lemma 3.1.3 and Theorem 3.1.4]). Let C be a nonempty closed convex subset of a Hilbert space $\mathrm{H}$. Then $\mathrm{P}_{\mathrm{C}}$ is a nonexpansive mapping from $\mathrm{H}$ onto $\mathrm{C}$ and $\mathrm{P}_{\mathrm{C}} \mathrm{x}$ is characterized by the following inequality

$$
\left\langle y-P_{C} x, x-P_{C} x\right\rangle \leqslant 0, \quad \forall y \in C .
$$

Lemma 2.10 ([7, Theorem 1.1.1]). Let $X$ and $Y$ be Banach spaces, $A$ be a continuous linear operator from $X$ to $Y$. Then $\mathrm{A}$ is weakly continuous. 
Finally, we need the following result for proving our main theorem in section 3.

Lemma 2.11 ([13, Lemma 3.1]). Let $\left\{u_{n}\right\}$ be a bounded sequence of a Hilbert space $H$. Let $s$ be a positive integer and $\mathrm{I}=\{1,2, \ldots, \mathrm{s}\}$. If $\lim _{n \rightarrow \infty}\left\|\mathrm{u}_{\mathrm{n}+1}-\mathrm{u}_{\mathrm{n}}\right\|=0$ and $\mathrm{x}^{*} \in \mathrm{\omega}_{w}\left(\mathrm{u}_{\mathrm{n}}\right)$, then for any $\mathrm{i} \in \mathrm{I}$, there exists a subsequence $\left\{u_{m_{k}}\right\}$ of $\left\{u_{n}\right\}$, depending on $i$, such that $u_{m_{k}} \rightarrow x^{*}$ and $\left[m_{k}\right]=i$ for all $k$, where $[n]$ denotes the s-mod function for each $n \geqslant 1$.

\section{Main results}

In this section, we establish the strong convergence of the viscosity iterative algorithm (1.7) to a solution of SCFP (1.2) for demicontractive mappings.

Assumption 3.1. Let $\mathrm{H}_{1}, \mathrm{H}_{2}$ be two real Hilbert spaces. We assume the following conditions:

(i) the solution set $\Omega$ of (1.8) is nonempty;

(ii) $\mathrm{U}_{i}: \mathrm{H}_{1} \rightarrow \mathrm{H}_{1}(1 \leqslant i \leqslant p)$ and $\mathrm{T}_{j}: \mathrm{H}_{2} \rightarrow \mathrm{H}_{2}(1 \leqslant j \leqslant q)$ are $\mu_{i}$-demicontractive and $\eta_{j^{-}}$ demicontractive, respectively;

(iii) $\mathrm{I}-\mathrm{U}_{i}(1 \leqslant i \leqslant p)$ and $\mathrm{I}-\mathrm{T}_{\mathbf{j}}(1 \leqslant j \leqslant q)$ are demiclosed at origin.

Let $\mu=\max _{1 \leqslant i \leqslant p} \mu_{i}$ and $\eta=\max _{1 \leqslant j \leqslant q} \eta_{i}$. Clearly $U_{i}$ is $\mu$-demicontractive for all $1 \leqslant i \leqslant p$ and $T_{j}$ is $\eta$-demicontractive for all $1 \leqslant j \leqslant q$.

Algorithm 3.2. Let $f$ be a fixed contraction on $U:=\cap_{i=1}^{p} \operatorname{Fix}\left(U_{i}\right) \neq \emptyset$ with coefficient $\alpha$ and $\lambda_{n} \in(0,1-\mu)$. Given arbitrary initial guess $x_{0}$ and two positive integers $p, q$, on assuming that the $n$th iterate $x_{n}$ has been constructed, we can define the $(n+1)$ th iterate by the following formula

$$
x_{n+1}=\alpha_{n} f\left(x_{n}\right)+\left(1-\alpha_{n}\right) U_{\lambda_{n}}\left(x_{n}-\rho_{n} A^{*}\left(I-T_{[n]}\right) A x_{n}\right), \quad n \geqslant 0,
$$

where $U_{\lambda_{n}}=\left(1-\lambda_{n}\right) I+\lambda_{n} U_{[n]}, U_{[n]}=U_{n(\bmod p)}, T_{[n]}=T_{n(\bmod q)}, A^{*}$ is the adjoint of a bounded linear operator $A$, and the step size $\rho_{n}$ is chosen in the following way

$$
\rho_{n}= \begin{cases}\frac{(1-\eta)\left\|\left(I-T_{[n]}\right) A x_{n}\right\|^{2}}{2\left\|A^{*}\left(I-T_{[n]}\right) A x_{n}\right\|^{2}}, & A x_{n} \neq T_{[n]}\left(A x_{n}\right), \\ 0, & \text { otherwise. }\end{cases}
$$

Lemma 3.3. Let Assumption 3.1 be satisfied. Given a bounded linear operator $A: H_{1} \rightarrow H_{2}$, let $\Omega \neq \emptyset$ and let $\left\{x_{n}\right\} \subset H_{1}$ be the sequence defined as in Algorithm 3.2. Assume that the sequence $\left\{x_{n}\right\}$ is bounded and all the sequences $\left\{\left\|x_{n}-y_{n}\right\|\right\},\left\{\left\|y_{n+1}-y_{n}\right\|\right\},\left\{\left\|\left(I-U_{[n]}\right) y_{n}\right\|\right\}$, and $\left\{\left\|\left(I-T_{[n]}\right) A x_{n}\right\|\right\}$ converge to zero, where $y_{n}:=x_{n}-\rho_{n} A^{*}\left(I-T_{[n]}\right) A x_{n}$. Then $\emptyset \neq \omega_{w}\left(x_{n}\right) \subset \Omega$.

Proof. Since $\left\{x_{n}\right\}$ is bounded, $\omega_{w}\left(x_{n}\right) \neq \emptyset$ and it also follows from the assumption $\left\|x_{n}-y_{n}\right\| \rightarrow 0$ that $\omega_{w}\left(x_{n}\right)=\omega_{w}\left(y_{n}\right)$. Now let $x^{*} \in \omega_{w}\left(x_{n}\right)=\omega_{w}\left(y_{n}\right)$. In view of $\left\|y_{n+1}-y_{n}\right\| \rightarrow 0$, for any fixed $i \in\{1,2, \ldots, s\}$ with $s=\max \{p, q\}$, use Lemma 2.11 with $u_{n}=y_{n}$ to get a subsequence $\left\{y_{m_{k}}\right\}$ of $\left\{y_{n}\right\}$ (depending on $i$ ) such that $y_{m_{k}} \rightarrow x^{*}$ and $\left[m_{k}\right]=i$ for all $k$. Based on $\left\|\left(I-U_{i}\right) y_{m_{k}}\right\|=\|(I-$ $\left.U_{\left[m_{k}\right]}\right) y_{m_{k}} \| \rightarrow 0$ and the demiclosedness of $I-U_{i}$ at the origin it results $x^{*} \in \operatorname{Fix}\left(U_{i}\right)$ for any fixed $i \in\{1,2, \ldots, p\}$; hence $x^{*} \in \cap_{i=1}^{p} \operatorname{Fix}\left(U_{i}\right)$. Observing that $x_{m_{k}} \rightarrow x^{*}$, apply Lemma 2.10 to see that $A x_{m_{k}} \rightarrow A x^{*}$. Based on $\left\|\left(I-T_{i}\right) A x_{m_{k}}\right\|=\left\|\left(I-T_{\left[m_{k}\right]}\right) A x_{m_{k}}\right\| \rightarrow 0$ and the demiclosedness property of $I-T_{i}$ at the origin, it follows that $A x^{*} \in \operatorname{Fix}\left(T_{i}\right)$ for any $i \in\{1,2, \ldots, q\}$ and so $A x^{*} \in \cap_{i=1}^{q} \operatorname{Fix}\left(T_{i}\right)$. Therefore $x^{*} \in \cap_{i=1}^{p} \operatorname{Fix}\left(U_{i}\right) \cap A^{-1}\left(\cap_{j=1}^{q} \operatorname{Fix}\left(T_{j}\right)\right)=\Omega$, completing the proof.

Theorem 3.4. Let Assumption 3.1 be satisfied. Given a bounded linear operators $\mathrm{A}: \mathrm{H}_{1} \rightarrow \mathrm{H}_{2}$, assume the SCFP (1.2) is consistent $(\Omega \neq \emptyset)$. If the sequences $\left\{\alpha_{n}\right\} \subset(0,1)$ and $\left\{\lambda_{n}\right\}$ satisfy the following conditions:

(i) $\lim _{n \rightarrow \infty} \alpha_{n}=0$ and $\sum_{n=0}^{\infty} \alpha_{n}=\infty$;

(ii) $0<\liminf _{n \rightarrow \infty} \lambda_{n} \leqslant \limsup \sup _{n \rightarrow \infty} \lambda_{n}<1-\mu$. 
The sequence $\left\{x_{n}\right\}$ generated by explicit algorithm (3.1) converges strongly to a point $\hat{x}=P_{\Omega} f(\hat{x})$, i.e., $\hat{x}$ satisfies the following variational inequality:

$$
\langle\hat{x}-\mathrm{f}(\hat{x}), \hat{x}-z\rangle \leqslant 0, \quad \forall z \in \Omega .
$$

Proof. By Lemma 2.7, $\mathrm{U}=\cap_{i=1}^{p} \operatorname{Fix}\left(\mathrm{U}_{i}\right)$ is closed convex in $\mathrm{H}_{1}$. Further, by Lemma 2.9, $\mathrm{P}_{\Omega} f: \mathrm{U} \rightarrow \Omega$ is a contraction and therefore admits a unique fixed point $\hat{x}$ of $P_{\Omega} f$, namely, $\hat{x}=P_{\Omega} f(\hat{x})$ is equivalent to the variational inequality (3.3) by the immediate aid of (2.4). Now from now on the proof is divided into three steps.

Step 1. We show that sequence $\left\{x_{n}\right\}$ is bounded. Let $y_{n}=x_{n}-\rho_{n} A^{*}\left(I-T_{[n]}\right) A x_{n}$, take $z \in \Omega$, it follows from (3.1) that

$$
\begin{aligned}
\left\|x_{n+1}-z\right\| & =\left\|\alpha_{n}\left(f\left(x_{n}\right)-z\right)+\left(1-\alpha_{n}\right)\left(U_{\lambda_{n}} y_{n}-z\right)\right\| \\
& \leqslant \alpha_{n}\left\|f\left(x_{n}\right)-f(z)\right\|+\left(1-\alpha_{n}\right)\left\|U_{\lambda_{n}} y_{n}-z\right\|+\alpha_{n}\|f(z)-z\| \\
& \leqslant \alpha \alpha_{n}\left\|x_{n}-z\right\|+\left(1-\alpha_{n}\right)\left\|U_{\lambda_{n}} y_{n}-z\right\|+\alpha_{n}\|f(z)-z\| .
\end{aligned}
$$

(a) If $\rho_{n} \neq 0$, from (2.2) and (2.3), we have

$$
\begin{aligned}
\left\|\mathrm{U}_{\lambda_{n}} y_{n}-z\right\|^{2} & \leqslant\left\|y_{n}-z\right\|^{2}-\lambda_{n}\left(1-\mu-\lambda_{n}\right)\left\|\left(I-U_{[n]}\right) y_{n}\right\|^{2} \\
& =\left\|x_{n}-\rho_{n} A^{*}\left(I-T_{[n]}\right) A x_{n}-z\right\|^{2}-\lambda_{n}\left(1-\mu-\lambda_{n}\right)\left\|\left(I-U_{[n]}\right) y_{n}\right\|^{2} \\
& \leqslant\left\|x_{n}-z\right\|^{2}-\frac{(1-\eta)^{2}}{4} \frac{\left\|\left(I-T_{[n]}\right) A x_{n}\right\|^{4}}{\left\|A^{*}\left(I-T_{[n]}\right) A x_{n}\right\|^{2}}-\lambda_{n}\left(1-\mu-\lambda_{n}\right)\left\|\left(I-U_{[n]}\right) y_{n}\right\|^{2} .
\end{aligned}
$$

Thus, we get

$$
\left\|\mathrm{U}_{\lambda_{n}} \mathrm{y}_{\mathrm{n}}-z\right\| \leqslant\left\|\mathrm{x}_{\mathrm{n}}-z\right\|
$$

By substituting (3.6) into (3.4), we have

$$
\begin{aligned}
\left\|x_{n+1}-z\right\| & \leqslant \alpha \alpha_{n}\left\|x_{n}-z\right\|+\left(1-\alpha_{n}\right)\left\|x_{n}-z\right\|+\alpha_{n}\|f(z)-z\| \\
& \leqslant\left[1-(1-\alpha) \alpha_{n}\right]\left\|x_{n}-z\right\|+\alpha_{n}\|f(z)-z\| \leqslant \max \left\{\left\|\left(x_{n}-z\right)\right\|, \frac{1}{1-\alpha}\|f(z)-z\|\right\}
\end{aligned}
$$

for all sufficiently large $n$. By induction, we arrive at

$$
\left\|x_{n}-z\right\| \leqslant \max \left\{\left\|x_{0}-z\right\|, \frac{1}{1-\alpha}\|f(z)-z\|\right\} .
$$

Thus the sequence $\left\{x_{n}\right\}$ is bounded, so is $\left\{f\left(x_{n}\right)\right\}$.

(b) If $\rho_{n}=0$, then $y_{n}=x_{n}$. In view of (2.3), we observe

$$
\left\|\mathrm{U}_{\lambda_{\mathrm{n}}} \mathrm{x}_{\mathrm{n}}-z\right\| \leqslant\left\|\mathrm{x}_{\mathrm{n}}-z\right\| .
$$

By applying the inequality (3.7) to (3.4), we conclude that the sequence $\left\{x_{n}\right\}$ and $\left\{f\left(x_{n}\right)\right\}$ are also bounded in a similar way as before.

Step 2. We show that the following inequality holds for $\hat{x}=P_{\Omega} f(\hat{x})$ :

$$
\left\|x_{n+1}-\hat{x}\right\|^{2} \leqslant\left(1-\alpha_{n}\right)\left\|x_{n}-\hat{x}\right\|^{2}+2 \alpha_{n}\left\langle f\left(x_{n}\right)-\hat{x}, x_{n+1}-\hat{x}\right\rangle .
$$

(a) If $\rho_{\mathrm{n}}=0$, it follows from (2.1) and (2.3) that

$$
\begin{aligned}
\left\|x_{n+1}-\hat{x}\right\|^{2} & \leqslant\left(1-\alpha_{n}\right)\left\|U_{\lambda_{n}} x_{n}-z\right\|^{2}+2 \alpha_{n}\left\langle f\left(x_{n}\right)-\hat{x}, x_{n+1}-\hat{x}\right\rangle \\
& \leqslant\left(1-\alpha_{n}\right)\left[\left\|x_{n}-z\right\|^{2}-\lambda_{n}\left(1-\lambda_{n}-\mu\right)\left\|\left(I-U_{[n]}\right) x_{n}\right\|^{2}\right]+2 \alpha_{n}\left\langle f\left(x_{n}\right)-\hat{x}, x_{n+1}-\hat{x}\right\rangle,
\end{aligned}
$$

which immediately yields

$$
\left\|x_{n+1}-\hat{x}\right\|^{2} \leqslant\left(1-\alpha_{n}\right)\left\|x_{n}-z\right\|^{2}+2 \alpha_{n}\left\langle f\left(x_{n}\right)-\hat{x}, x_{n+1}-\hat{x}\right\rangle .
$$

Thus the inequality (3.8) is obtained. 
(b) If $\rho_{\mathrm{n}} \neq 0$, by (2.1) and (3.5) replaced with $z=\hat{x}$, we obtain

$$
\begin{aligned}
\left\|x_{n+1}-\hat{x}\right\|^{2} \leqslant & \left(1-\alpha_{n}\right)\left\|U_{\lambda_{n}} y_{n}-\hat{x}\right\|^{2}+2 \alpha_{n}\left\langle f\left(x_{n}\right)-\hat{x}, x_{n+1}-\hat{x}\right\rangle \\
\leqslant & \left(1-\alpha_{n}\right)\left[\left\|x_{n}-\hat{x}\right\|^{2}-\frac{(1-\eta)^{2}}{4} \frac{\left\|\left(I-T_{[n]}\right) A x_{n}\right\|^{4}}{\left\|A^{*}\left(I-T_{[n]}\right) A x_{n}\right\|^{2}}\right. \\
& \left.-\lambda_{n}\left(1-\lambda_{n}-\mu\right)\left\|\left(I-U_{[n]}\right) y_{n}\right\|^{2}\right]+2 \alpha_{n}\left\langle f\left(x_{n}\right)-\hat{x}, x_{n+1}-\hat{x}\right\rangle,
\end{aligned}
$$

which quickly gives the inequality (3.8).

Step 3. We show that $x_{n} \rightarrow \hat{x}$. Setting $s_{n}:=\left\|x_{n}-\hat{x}\right\|^{2}$, the proof of this step is divided into two cases.

Case I. Assume that there is a positive integer $n_{0}$ such that the sequence $\left\{s_{n}\right\}$ is decreasing for all $n \geqslant n_{0}$, then the sequence $\left\{s_{n}\right\}$ is obviously convergent. First, we claim that

$$
\limsup _{n \rightarrow \infty}\left\langle f(\hat{x})-\hat{x}, x_{n}-\hat{x}\right\rangle \leqslant 0 .
$$

(a) If $\rho_{n}=0$, i.e., $x_{n}=y_{n}$, by a simple inequality eliminating $\left(1-\alpha_{n}\right)$ in (3.9) and based on the boundedness of $\left\{x_{n}\right\}$ and $\left\{f\left(x_{n}\right)\right\}$, we obtain

$$
\lambda_{n}\left(1-\lambda_{n}-\mu\right)\left\|\left(I-U_{[n]}\right) x_{n}\right\|^{2} \leqslant s_{n}-s_{n+1}+\alpha_{n} K,
$$

where $K:=\sup _{n \in N}\left\{2\left\langle f\left(x_{n}\right)-\hat{x}, x_{n+1}-\hat{x}\right\rangle\right\}$. By the aids of convergence of the sequence $\left\{s_{n}\right\}$ and the conditions (i) and (ii), it follows that

$$
\left\|\left(\mathrm{I}-\mathrm{U}_{[\mathrm{n}]}\right) \mathrm{x}_{\mathrm{n}}\right\| \rightarrow 0 .
$$

Since $A x_{n}=T_{[n]} A x_{n}$ in (3.2), we also have

$$
\left\|\left(\mathrm{I}-\mathrm{T}_{[\mathrm{n}]}\right) A \mathrm{x}_{\mathrm{n}}\right\| \rightarrow 0 .
$$

Next we claim that $\left\|x_{n+1}-x_{n}\right\| \rightarrow 0$. Indeed, since $U_{\lambda_{n}} x_{n}-x_{n}=\lambda_{n}\left(U_{[n]} x_{n}-x_{n}\right)$, an easy calculation yields

$$
\begin{aligned}
\left\|x_{n+1}-x_{n}\right\| & \leqslant \alpha_{n}\left\|f\left(x_{n}\right)-x_{n}\right\|+\left(1-\alpha_{n}\right)\left\|x_{n}-U_{\lambda_{n}} x_{n}\right\| \\
& \leqslant \alpha_{n}\left\|f\left(x_{n}\right)-x_{n}\right\|++\lambda_{n}\left\|\left(I-U_{[n]}\right) x_{n}\right\| \rightarrow 0
\end{aligned}
$$

by the help of (3.12) and $\alpha_{n} \rightarrow 0$. Now choose a subsequence $\left\{x_{n_{k}}\right\} \subset\left\{x_{n}\right\}$ such that $x_{n_{k}} \rightarrow u \in H_{1}$ and

$$
\limsup _{n \rightarrow \infty}\left\langle f(\hat{x})-\hat{x}, x_{n}-\hat{x}\right\rangle=\lim _{k \rightarrow \infty}\left\langle f(\hat{x})-\hat{x}, x_{n_{k}}-\hat{x}\right\rangle
$$

by boundedness of $\left\{x_{n}\right\}$. Obviously, $u \in \omega_{w}\left(x_{n}\right) \subset \Omega$ because all hypotheses of Lemma 3.3 are fulfilled with $x_{n}=y_{n}$. Therefore, it follows from (3.13), (3.3), and $x_{n_{k}} \rightarrow u \in \Omega$ that

$$
\limsup _{n \rightarrow \infty}\left\langle f(\hat{x})-\hat{x}, x_{n}-\hat{x}\right\rangle=\langle f(\hat{x})-\hat{x}, u-\hat{x}\rangle \leqslant 0,
$$

which proves the inequality (3.11).

(b) If $\rho_{n} \neq 0$, by using a simple inequality with no $\left(1-\alpha_{n}\right)$ in (3.10) and the boundedness of $\left\{x_{n}\right\}$ and $\left\{f\left(x_{n}\right)\right\}$, we have

$$
\lambda_{n}\left(1-\lambda_{n}-\mu\right)\left\|\left(I-U_{[n]}\right) y_{n}\right\|^{2}+\frac{(1-\eta)^{2}}{4}\left(\frac{\left\|\left(I-T_{[n]}\right) A x_{n}\right\|^{2}}{\left\|A^{*}\left(I-T_{[n]}\right) A x_{n}\right\|}\right)^{2} \leqslant s_{n}-s_{n+1}+\alpha_{n} K
$$


Using the convergence of $\left\{s_{n}\right\}$ and the conditions (i) and (ii) we obtain that

$$
\left\|\left(\mathrm{I}-\mathrm{U}_{[\mathrm{n}]}\right) \mathrm{y}_{\mathrm{n}}\right\| \rightarrow 0
$$

and

$$
\frac{\left\|\left(\mathrm{I}-\mathrm{T}_{[\mathrm{n}]}\right) A x_{\mathrm{n}}\right\|^{2}}{\left\|A^{*}\left(\mathrm{I}-\mathrm{T}_{[\mathrm{n}]}\right) A x_{\mathrm{n}}\right\|} \rightarrow 0
$$

Moreover,

$$
\frac{1}{\|A\|}\left\|\left(I-T_{[n]}\right) A x_{n}\right\|=\frac{\left\|\left(I-T_{[n]}\right) A x_{n}\right\|}{\|A\|}=\left\|\left(I-T_{[n]}\right) A x_{n}\right\| \frac{\left\|\left(I-T_{[n]}\right) A x_{n}\right\|}{\|A\|\left\|\left(I-T_{[n]}\right) A x_{n}\right\|} \leqslant \frac{\left\|\left(I-T_{[n]}\right) A x_{n}\right\|^{2}}{\left\|A *\left(I-T_{[n]}\right) A x_{n}\right\|},
$$

and so

$$
\left\|\left(\mathrm{I}-\mathrm{T}_{[\mathrm{n}]}\right) A x_{\mathrm{n}}\right\| \rightarrow 0 .
$$

On one hand, since

$$
\left\|x_{n}-y_{n}\right\|=\rho_{n}\left\|A^{*}\left(I-T_{[n]}\right) A x_{n}\right\|=\frac{(1-\eta)}{2} \frac{\left\|\left(I-T_{[n]}\right) A x_{n}\right\|^{2}}{\left\|A^{*}\left(I-T_{[n]}\right) A x_{n}\right\|} \rightarrow 0
$$

by (3.15), it follows that

$$
\begin{aligned}
\left\|x_{n+1}-x_{n}\right\| & \leqslant \alpha_{n}\left\|f\left(x_{n}\right)-x_{n}\right\|+\left(1-\alpha_{n}\right)\left\|x_{n}-u_{\lambda_{n}} y_{n}\right\| \\
& \leqslant \alpha_{n}\left\|f\left(x_{n}\right)-x_{n}\right\|+\left\|x_{n}-y_{n}\right\|+\left\|y_{n}-U_{\lambda_{n}} y_{n}\right\| \\
& =\alpha_{n}\left\|f\left(x_{n}\right)-x_{n}\right\|+\left\|x_{n}-y_{n}\right\|+\lambda_{n}\left\|\left(I-U_{[n]}\right) y_{n}\right\| \rightarrow 0
\end{aligned}
$$

by the aids of $\alpha_{n} \rightarrow 0,(3.14)$, and (3.16). Then we also have

$$
\left\|y_{n+1}-y_{n}\right\| \leqslant\left\|y_{n+1}-x_{n+1}\right\|+\left\|x_{n+1}-x_{n}\right\|+\left\|x_{n}-y_{n}\right\| \rightarrow 0 .
$$

For employing the proof in Case I, choose the subsequence $\left\{x_{n_{k}}\right\} \subset\left\{x_{n}\right\}$ which satisfies (3.13) and $x_{n_{k}} \rightarrow$ $u \in H_{1}$. Since all the assumptions of Lemma 3.3 are fulfilled, we conclude that $u \in w_{w}\left(x_{n}\right)=w_{w}\left(y_{n}\right) \subset$ $\Omega$, which immediately gives the required inequality (3.11). Now we prove that $x_{n} \rightarrow \hat{x}$. In fact, use $\left\|x_{n+1}-x_{n}\right\| \rightarrow 0$ and (3.11) to induce that

$$
\limsup _{n \rightarrow \infty}\left\langle f(\hat{x})-\hat{x}, x_{n+1}-\hat{x}\right\rangle \leqslant 0 .
$$

Then since all the assumptions of Lemma 2.4 are fulfilled, we conclude that $x_{\mathfrak{n}} \rightarrow \hat{x}$.

Case II. Suppose that there exists a subsequence $\left\{s_{n_{i}}\right\}$ of $\left\{s_{n}\right\}$ such that $s_{n_{i}}<s_{n_{i}+1}$ for all $i \geqslant 0$. By applying Lemma 2.8, we can take a nondecreasing sequence $\{\tau(n)\}_{n} \geqslant n_{0}$ of integers such that $\tau(n) \rightarrow \infty$ and

$$
s_{\tau(n)} \leqslant s_{\tau(n)+1}, s_{n} \leqslant s_{\tau(n)+1}, \quad \forall n \geqslant n_{0} .
$$

First, we show that

$$
\limsup _{n \rightarrow \infty}\left\langle f(\hat{x})-\hat{x}, \chi_{\tau(n)}-\hat{x}\right\rangle \leqslant 0 .
$$

(a) If $\rho_{\mathcal{\tau}(n)}=0$, by using a simple inequality with no $\left(1-\alpha_{n}\right)$ in (3.9), (3.17), and the boundedness of $\left\{x_{n}\right\}$ and $\left\{f\left(x_{n}\right)\right\}$, we have

$$
\lambda_{\tau(n)}\left(1-\mu-\lambda_{\tau(n)}\right)\left\|\left(I-U_{[\tau(n)]}\right) x_{\tau(n)}\right\|^{2} \leqslant s_{\tau(n)}-s_{\tau(n)+1}+\alpha_{\tau(n)} K_{0} \leqslant \alpha_{\tau(n)} K_{0},
$$

where $K_{0}:=\sup _{n \geqslant n_{0}}\left\{2\left\langle f\left(x_{\tau(n)}\right)-\hat{x}, x_{\tau(n)+1}-\hat{x}\right\rangle\right\}$. So,

$$
\left\|\left(\mathrm{I}-\mathrm{U}_{[\tau(n)]}\right) x_{\tau(n)}\right\| \rightarrow 0 .
$$


Since $A x_{\tau(n)}=T_{[\tau(n)]} A x_{\tau(n)}$ in (3.2), it is obvious that

$$
\left\|\left(\mathrm{I}-\mathrm{T}_{[\tau(\mathrm{n})]}\right) A x_{\tau(\mathrm{n})}\right\| \rightarrow 0 .
$$

By slightly modifying the proof of (a) in Case I we could prove

$$
\left\|x_{\mathcal{\tau}(n)+1}-x_{\mathcal{\tau}(n)}\right\| \rightarrow 0 .
$$

Now use Lemma 3.3, after equipped with $\left\{x_{\tau(n)}\right\}$ in place of $\left\{x_{n}\right\}$, to establish (3.18).

(b) If $\rho_{\tau(n)} \neq 0$, it follows from (3.10) and (3.17) that

$$
\begin{gathered}
\lambda_{\tau(n)}\left(1-\lambda_{\tau(n)}-\mu\right)\left\|\left(I-U_{[\tau(n)]}\right) y_{\tau(n)}\right\|^{2}+\frac{(1-\eta)^{2}}{4} \frac{\left\|\left(I-T_{[\tau(n)]}\right) A x_{\tau(n)}\right\|^{4}}{\left\|A^{*}\left(I-T_{[\tau(n)]}\right) A x_{\tau(n)}\right\|^{2}} \\
\leqslant s_{\tau(n)}-s_{\tau(n)+1}+\alpha_{\tau(n)} K_{0} \leqslant \alpha_{\tau(n)} K_{0} \rightarrow 0
\end{gathered}
$$

by the boundedness of $\left\{x_{\mathcal{\tau}(n)}\right\}$ and $\left\{f\left(x_{\tau(n)}\right)\right\}$ and $\alpha_{\mathcal{\tau}(n)} \rightarrow 0$. In view of two conditions (i) and (ii), the above inequality yields

$$
\left\|\left(I-U_{[\tau(n)]}\right) y_{\tau(n)}\right\| \rightarrow 0 \text { and } \frac{\left\|\left(I-T_{[\tau(n)]}\right) A x_{\tau(n)}\right\|^{2}}{\left\|A^{*}\left(I-T_{[\tau(n)]}\right) A x_{\tau(n)}\right\|} \rightarrow 0 .
$$

Now mimicking the proof of $(b)$ in Case 1 we easily prove that all the sequences $\left.\left\{\|\left(I-T_{[\tau(n)]}\right) A x_{\tau(n)}\right) \|\right\}$, $\left\{\left\|x_{\tau(n)}-y_{\tau(n)}\right\|\right\},\left\{\left\|x_{\tau(n)+1}-x_{\tau(n)}\right\|\right\}$, and $\left\{\left\|y_{\tau(n)}-y_{\tau(n)+1}\right\|\right\}$ converge to zero. Since all the hypotheses of Lemma 3.3 are fulfilled, if we choose a subsequence $\left\{\tau\left(k_{n}\right)\right\}$ of $\{\tau(n)\}_{n} \geqslant n_{0}$ such that $x_{\tau\left(k_{n}\right)} \rightarrow v \in H_{1}$ and

$$
\limsup _{n \rightarrow \infty}\left\langle f(\hat{x})-\hat{x}, x_{\tau(n)}-\hat{x}\right\rangle=\lim _{n \rightarrow \infty}\left\langle f(\hat{x})-\hat{x}, x_{\tau\left(k_{n}\right)}-\hat{x}\right\rangle,
$$

then $v \in \omega_{\mathcal{w}}\left(x_{\tau(n)}\right)=\omega_{\mathcal{w}}\left(y_{\tau(n)}\right) \subset \Omega$; so this equality becomes

$$
\limsup _{n \rightarrow \infty}\left\langle f(\hat{x})-\hat{x}, x_{\tau(n)}-\hat{x}\right\rangle=\langle f(\hat{x})-\hat{x}, v-\hat{x}\rangle \leqslant 0
$$

for $\hat{x}=P_{\Omega}(f(\hat{x})) ;(3.18)$ is thus obtained. Since $\left\|x_{\tau(n)+1}-x_{\tau(n)}\right\| \rightarrow 0$, it follows from (3.18) that

$$
\limsup _{n \rightarrow \infty}\left\langle f(\hat{x})-\hat{x}, x_{\tau(n)+1}-\hat{x}\right\rangle \leqslant 0 .
$$

Secondly we show that $x_{n} \rightarrow 0$. Indeed, since $s_{\tau(n)} \leqslant s_{\tau(n)+1}$ for all $n \geqslant n_{0}$, a slight transformation of (3.8) yields

$$
\alpha_{\tau(n)} s_{\tau(n)+1}+\left(1-\alpha_{\tau(n)}\right)\left(s_{\tau(n)+1}-s_{\tau(n)}\right) \leqslant 2 \alpha_{\tau(n)}\left\langle f\left(x_{\tau(n)}\right)-\hat{x}, x_{\tau(n)+1}-\hat{x}\right\rangle
$$

and so

$$
\alpha_{\tau(\mathfrak{n})} s_{\tau(\mathfrak{n})+1} \leqslant 2 \alpha_{\tau(\mathfrak{n})}\left\langle f\left(x_{\tau(n)}\right)-\hat{x}, x_{\tau(n)+1}-\hat{x}\right\rangle \Rightarrow 0 \leqslant s_{\tau(n)+1} \leqslant 2\left\langle f\left(x_{\tau(n)}\right)-\hat{x}, x_{\tau(n)+1}-\hat{x}\right\rangle
$$

because $\alpha_{n} \in(0,1)$. Now taking the limit superior on both sides as $n \rightarrow \infty$ and using (3.19), we obtain $s_{\tau(n)+1} \rightarrow 0$; hence $s_{n} \rightarrow 0$ because of $s_{n} \leqslant s_{\tau(n)+1}$ for all $n \geqslant n_{0}$ in (3.17), completing the proof.

Remark 3.5. The main result of Theorem 3.4 is a cyclic explicit version of Theorem 3.2 in [6]. If we take $p=q=1$, the algorithm (3.1) equipped with $\lambda_{n}=\lambda$ for all $n$ reduces to (1.6).

Finally we shall give an example which satisfies all the conditions of the solution set $\Omega$ of the MCFP (1.2), the mappings $\left\{U_{i}\right\}_{i=1}^{p}$, and $\left\{T_{j}\right\}_{j=1}^{q}$ in Assumption 3.1. 
Example 3.6. Let $\mathrm{H}_{1}=\mathrm{H}_{2}=\mathrm{H}_{3}=\ell_{2}$ and let $i \in\{1,2, \ldots, p\}$ and $j \in\{1,2, \ldots, q\}$ be arbitrarily fixed. Let $U_{i}, T_{j}: \ell_{2} \rightarrow \ell_{2}$ be defined by $U_{i} x=-2 i x$ and $T_{j} x=-(2 j+1) x$ for all $x \in \ell_{2}$. Then it is easy to see that $\cap_{i=1}^{p} \operatorname{Fix}\left(U_{i}\right)=\{0\}=\cap_{j=1}^{q} \operatorname{Fix}\left(T_{j}\right)$ and $A 0=0$. Thus $\Omega=\{0\} \neq \emptyset$. Also $U_{i}$ is $\mu_{i}$-demicontractive and $T_{j}$ is $\eta_{j}$-demicontractive by Example 2.5 in [12], where $\mu_{i}=\frac{2 i-1}{2 i+1}, \mu=\max _{1 \leqslant i \leqslant p}, \frac{2 i-1}{2 i+1}, \mu_{i}=\frac{2 p-1}{2 p+1}, \eta_{j}=\frac{j}{j+1}$, and $\eta=\max _{1 \leqslant j \leqslant q} \eta_{j}=\frac{q}{q+1}$; then $I-U_{i}$ and $I-T_{j}$ are demiclosed at 0 by Remark 2.12 in [12].

Next we give an example which satisfies the conditions (i) and (ii) in Theorem 3.4.

Example 3.7. We can take $\alpha_{n}=\frac{1}{n}$ and $\lambda_{n}=\frac{k}{k+1}(1-\mu)+(-1)^{n} \frac{1}{n}$ for all $n$, where $k \in \mathbb{N}$ is arbitrarily fixed. Then $\lim _{n \rightarrow \infty} \lambda_{n}=\frac{k}{k+1}(1-\mu)<1-\mu$, which satisfies the condition (ii) of Theorem 3.4.

\section{Acknowledgment}

The second and third authors were supported, respectively, by the Research Grant of Pukyong National University (2017 year), and the Natural Science Foundation of China (No.11401388), Zhejiang Provincial Natural Science Foundation of China (No.LQ13A010007).

\section{References}

[1] Y. Censor, T. Elfving, A multiprojection algorithm using Bregman projections in a product space, Numer. Algorithms, 8 (1994), 221-239. 1

[2] Y. Censor, A. Segal, The split common fixed point problem for directed operators, J. Convex Anal., 16 (2009), 587-600. 1, 1

[3] H. H. Cui, M. L. Su, F. H. Wang, Damped projection method for split common fixed point problems, J. Inequal. Appl., 2013 (2013), 10 pages. 1

[4] H. H. Cui, F. H. Wang, Iterative methods for the split common fixed point problem in Hilbert spaces, Fixed Point Theory Appl., 2014 (2014), 8 pages. 2.5, 2.6

[5] B. Eicke, Iteration methods for convexly constrained ill-posed problems in Hilbert space, Numer. Funct. Anal. Optim., 13 (1992), 413-429. 1

[6] H. M. He, S. Y. Liu, R. D. Chen, X. Y. Wang, Strong convergence results for the split common fixed point problem, J. Nonlinear Sci. Appl. 9 (2016), 5332-5343. 1, 1, 3.5

[7] M. C. Joshi, R. K. Bose, Some topics in nonlinear functional analysis, John Wiley \& Sons, New York, (1985). 2.10

[8] P. E. Maingé, Strong convergence of projected subgradient methods for nonsmooth and nonstrictly convex minimization, Set-Valued Anal., 16 (2008), 899-912. 2.8

[9] G. Marino, H.-K. Xu, Weak and strong convergence theorems for strict pseudo-contractions in Hilbert spaces, J. Math. Anal. Appl., 329 (2007), 336-346. 2.2, 2.7

[10] A. Moudafi, The split common fixed-point problem for demicontractive mappings, Inverse Problems, 26 (2010), 6 pages. $1,1,2.6$

[11] W. Takahashi, Nonlinear Functional Analysis, Yokohama Publishers, Yokohama, (2000). 2.9

[12] Y. Q. Wang, T. H. Kim, Simultaneous iterative algorithm for the split equality fixed-point problem of demicontractive mappings, J. Nonlinear Sci. Appl., 10 (2017), 154-165. 3.6

[13] Y. Q. Wang, T.-H. Kim, X. L. Fang, H. M. He, The split common fixed-point problem for demicontractive mappings and quasi-nonexpansive mappings, J. Nonlinear Sci. Appl., 10 (2017), 2976-2985. 2.11

[14] F. H. Wang, H.-K. Xu, Cyclic algorithms for split feasibility problems in Hilbert spaces, Nonlinear Anal., 74 (2011), 4105-4111. 1, 1, 1

[15] H. K. Xu, An iterative approach to quadratic optimization, J. Optim. Theory Appl., 116 (2003), 659-678. 2.4 